American Journal of Infectious Diseases 7 (2): 28-31, 2011

ISSN 1553-6203

(C) 2011 Science Publications

\title{
Is Wright Test an Appropriate Screening Test for Diagnosis of Brucellosis?
}

\author{
${ }^{1}$ Behzad Mohsenpour, ${ }^{1}$ Shahla Afrasiabian, \\ ${ }^{1}$ Katayoon Hajibagheri and ${ }^{2}$ Ebrahim Ghaderi \\ ${ }^{1}$ Department of Infectious Diseases, \\ ${ }^{2}$ Department of Epidemiology, Faculty of Medicine, \\ Kurdistan University of Medical Sciences, Sanandaj, Iran
}

\begin{abstract}
Problem statement: Diagnosis of brucellosis is generally based on culture, polymerase chain reaction and serology. The first two methods are not accessible in all parts of world and are expensive. The routine method for diagnosis of brucellosis is considering Wright test as the first screening test; if the results are Wright positive' Wright would be the next choice otherwise 2ME would be requested. This method of laboratory data collection is not appropriate and it is probable to have some cases of brucellosis missed and in clinical practice we observed that some cases of brucellosis are Wright negative but Coombs' Wright positive. Approach: In this study we calculated sensitivity, specificity, positive predictive value, negative predictive value and likelihood ratio of Wright and Coombs' Wright in brucellosis suspected patients. Results: 122 patients suspected to brucellosis were studied. 53.3\% were female. Sensitivity and specificity Positive Predictive Values (PPV) and Negative Predictive Values (NPV) of Wright were $32.5 \%\left(\mathrm{CI}_{95 \%}: 22.8-42.3\right), 96.4 \%\left(\mathrm{CI}_{95 \%}\right.$ : 89.5-100), 96.6\% ( $\mathrm{CI}_{95 \%}$ : 0.9-100) and $93.1 \%\left(\mathrm{CI}_{95 \%}: 83.8-100\right)$ respectively. Sensitivity, specificity, positive predictive value and negative predictive value for Coombs' Wright were $97.7 \%$ ( $\mathrm{CI}_{95 \%}$ : 94.6$100), 100 \%\left(\mathrm{CI}_{95 \%}: 100-100\right), 100 \%\left(\mathrm{CI}_{95 \%}: 100-100\right)$ and $93.1 \%\left(\mathrm{CI}_{95 \%}: 83.8-100\right)$ respectively. Conclusion: Coombs' Wright is more sensitive than Wright for diagnosis of brucellosis. Instead of considering Wright, Coombs' Wright and 2ME (mercaptoethanol) tests and interpretation of these three test we can just apply Coombs' Wright and 2ME to reduce the expenditures and use a more sensitive test for diagnosis of brucellosis.
\end{abstract}

Key words: Diagnostic test, Negative Predictive Values (NPV), Positive Predictive Values (PPV), suspected patients, Wright positive, infectious diseases

\section{INTRODUCTION}

Brucellosis is one of the most common zoonotic diseases in many region of the world, especially in Iran and its incidence is increasing (Aliskan, 2008; Karami and Movassagh, 2010). Infection is transmitted by dairy products like milk, cheese and contact with infected animal and aerosol (Hatami et al., 2010; Rajaii et al., 2006). Signs and symptoms of disease are extremely various. It can mimic many infectious diseases and involve any organ in human body (Gomez et al., 2008; Rajaii et al., 2006). Laboratory tests used for diagnosis of brucellosis include: blood culture, bone marrow culture, Polymerase Chain Reaction (PCR), ELISA, agglutination test and Rose Bengal (Abdi-Liae, et al., 2007; Aliskan, 2008; Heydari et al., 2008). The most useful and common test which is used is the standard tube agglutination test called Wright. Two other complementary tests are 2-Mercaptoethanol (2ME) and Coombs' Wright (Abdi-Liae et al., 2007; Aliskan, 2008; Hatami et al., 2010; Heydari et al., 2008).

Now the first screening test is Wright and many physicians request this test as the first step in diagnosis of brucellosis. If result of Wright is negative, Coombs' Wright would be requested. Some of the patients who are infected with brucellosis have negative result of Wright test. This is a problem in diagnosis of brucellosis and it makes it necessary to

Corresponding Author: Katayoon Hajibagheri Department of Infectious Diseases, Faculty of Medicine, Kurdistan University of Medical Sciences, Pasdaran Ave, Sanandaj, Iran Tel: +98-9181719043 
have more laboratory tests and more cost for the patient. Now we believe that if a patient with signs and symptoms of brucellosis never received any treatment for the disease, through a single Coombs' Wright test his/her brucellosis could be diagnosed; because this test is as effective as Wright and in cases of chronic disease, presence of incomplete antibody or blocking antibody the test could be positive (AbdiLiae et al., 2007; Afsharpaiman and Mamishi, 2008; Heydari et al., 2008; Karami and Movassagh, 2010).

Thus we decided to do this study for finding the best screening test and to decrease the cost and number of unnecessary laboratory test through applying a single test and to prevent confusion in interpretation of tests.

\section{MATERIALS AND METHODS}

It is an analytical cross-sectional study. In this study 122 suspected patients to brucellosis who referred to infectious disease clinic were included. All patients were examined completely and results including past medical history, physical examination and laboratory data (Count Blood Cell, Wright, 2ME, Coombs' Wright, liver enzyme test and ESR) were recorded in a questionnaire. Definite diagnosis of brucellosis was achieved by clinical and laboratory findings. Leucopenia, anemia, thrombocytopenia were defined as WBC $<5000$ cell/ $\mu \mathrm{L}$, hemoglobin $<13 \mathrm{~g}$ $\mathrm{d} \tilde{\mathrm{L}} 1$ in men or $<12 \mathrm{~g} \mathrm{d \tilde {L } 1}$ in women and platelet $<150000$, respectively. Wright test was considered positive if its titer was equal or greater than $1 / 160$ and Coombs' Wright was considered positive if its titer was equal or greater than $1 / 40$ as recommended by Iranian National center of diseases control. The data was entered to SPSS version 11.5 software. Chisquare, Fisher exact and Mann-Whitney U tests were used for analyzing the data. Also, Sensitivity, specificity, positive predictive value, negative predictive value and Likelihood ratio for Wright and Coombs' Wright were calculated as shown below (Table 1).

Table 1: Method of diagnostic index calcultion

\begin{tabular}{lcc}
\hline \multicolumn{3}{c}{ Brucellosis } \\
Result of the test & + & - \\
\hline+ & $\mathrm{a}$ & $\mathrm{b}$ \\
- & $\mathrm{c}$ & $\mathrm{d}$ \\
\hline We used these formula for calculating diagnostic indexes; Sensitivity: \\
a/(a+c), Specificity: d/(b+d), Positive predictive value: a/(a+b), \\
Negative predictive value: d/(c+d), Agreement: (a+d)/(a+b+c+d), \\
Positive Likelihood ratio: sensitivity/ (1-specificity), Negative \\
Likelihood ratio: (1-sensitivity)/ specificity
\end{tabular}

\section{RESULTS}

Among 122 patients suspected to brucellosis, 65 $(53.3 \%)$ were female and $70(57.4 \%)$ were urban. The mean of age was $40.2( \pm 17)$ years. The symptoms are presented in Table 1. There were no significant differences in symptoms between brucellosis and nonbrucellosis patients. Also, there were no significant differences between two groups in white blood cell, lymphocyte, neutrophil, monocyte and eosinophil. Leucopenia, anemia, thrombocytopenia were observed in $21.8,21.7$ and $10.8 \%$ of patients respectively (Table 2-4).

Table 2: Sex ratio, sign and symptom prevalence in two groups of study

\begin{tabular}{|c|c|c|c|c|}
\hline Variable & & $\begin{array}{l}\text { Non- } \\
\text { brucellosis }\end{array}$ & Brucellosis & P-value \\
\hline \multirow{2}{*}{ Sex } & Female & $17(63 \%)$ & $45(50.6 \%)$ & 0.25 \\
\hline & Male & $10(37 \%)$ & $44(49.4 \%)$ & \\
\hline \multirow[t]{2}{*}{ Fever } & No & $15(55.6 \%)$ & $27(32.1 \%)$ & 0.03 \\
\hline & Yes & $12(44.4 \%)$ & $57(67.9 \%)$ & \\
\hline \multirow[t]{2}{*}{ Sweating } & No & $11(42.3 \%)$ & $27(32.9 \%)$ & 0.38 \\
\hline & Yes & $15(57.7 \%)$ & $55(67.1 \%)$ & \\
\hline \multirow[t]{2}{*}{ Anorexia } & No & $17(65.4 \%)$ & $37(44.6 \%)$ & 0.06 \\
\hline & Yes & $9(34.6 \%)$ & $46(55.4 \%)$ & \\
\hline \multirow[t]{2}{*}{ Myalgia } & No & $5(18.5 \%)$ & $12(14.5 \%)$ & 0.61 \\
\hline & Yes & $22(81.5 \%)$ & $71(85.5 \%)$ & \\
\hline \multirow[t]{2}{*}{ Chill } & No & $16(59.3 \%)$ & $44(53 \%)$ & 0.57 \\
\hline & Yes & $11(40.7 \%)$ & $39(47 \%)$ & \\
\hline \multirow[t]{2}{*}{ Headache } & No & $8(29.6 \%)$ & $30(35.7 \%)$ & 0.56 \\
\hline & Yes & $19(70.4 \%)$ & $54(64.7 \%)$ & \\
\hline \multirow[t]{2}{*}{ Vomiting } & No & $25(92.6 \%)$ & $81(94.2 \%)$ & $0.67 \dagger$ \\
\hline & Yes & $2(7.4 \%)$ & $5(5.8 \%)$ & \\
\hline \multirow[t]{2}{*}{ Constipation } & No & $23(85.2 \%)$ & $68(81 \%)$ & $0.62 \dagger$ \\
\hline & Yes & $4(14.8 \%)$ & $16(19 \%)$ & \\
\hline \multirow[t]{2}{*}{ Lymphadenopathy } & No & $26(96.3 \%)$ & $79(95.2 \%)$ & $0.8 \dagger$ \\
\hline & Yes & $1(3.7 \%)$ & $4(4.8 \%)$ & \\
\hline \multirow[t]{2}{*}{ Splenomegaly } & No & $27(100 \%)$ & $77(93.9 \%)$ & $0.19 \dagger$ \\
\hline & Yes & 0 & $5(6.1 \%)$ & \\
\hline \multirow[t]{2}{*}{ Cough } & No & $21(77.8 \%)$ & $65(76.5 \%)$ & 0.89 \\
\hline & Yes & $6(22.2 \%)$ & $20(23.5 \%)$ & \\
\hline \multirow[t]{2}{*}{ Low back pain } & No & $4(14.8 \%)$ & $13(15.3 \%)$ & $0.95 \dagger$ \\
\hline & Yes & $23(85.2 \%)$ & $72(84.7 \%)$ & \\
\hline \multirow[t]{2}{*}{ Pelvic pain } & No & $4(14.8 \%)$ & $22(26.2 \%)$ & $0.3 \dagger$ \\
\hline & Yes & $23(85.2 \%)$ & $62(73.8 \%)$ & \\
\hline
\end{tabular}

$\dagger$ Fisher exact test was used for analysing.

Table 3: Median (Minimum - Maximum) of laboratory data finding (complete blood count) in two groups of study

\begin{tabular}{llll}
\hline & Non-brucellosis & Brucellosis & P-value \\
\hline White blood cell & $6300(4000-21000)$ & $6700(2500-14000)$ & 0.91 \\
Lymphocyte (\%) & $37(10-60)$ & $38(17-70)$ & 0.27 \\
Neutrophil (\%) & $60(38-90)$ & $58(27-80)$ & 0.24 \\
Monocyte (\%) & $1(0-2)$ & $0(0-10)$ & 0.17 \\
Eosinophil (\%) & $0(0-5)$ & $1(0-9)$ & 0.13 \\
\hline
\end{tabular}

Mann-Whitney U test was used for analysing.

Table 4: Frequency and percentage of leucopenia, anemia and thrombocytopenia in brucellosis patients

\begin{tabular}{lll}
\hline Variable & No patients & Frequency $(\%)$ \\
\hline Leucopenia & 87 & $19(21.8 \%)$ \\
Anemia & 83 & $18(21.7 \%)$ \\
Thrombocytopenia & 83 & $9(10.8 \%)$ \\
\hline
\end{tabular}

Leucopenia: $\mathrm{WBC}<5000$ : Anemia: $\mathrm{Hb}<13$ in male or $<12$ in female: Thrombocytopenia: PLT $<150000$ 
Am. J. Infect. Dis., 7 (2): 28-31, 2011

Table 5: Diagnostic index of Wright test in diagnosis of patients suspected to brucellosis

\begin{tabular}{llll}
\hline & & Brucellosis & \\
& & Positive & Negative \\
\hline \multirow{2}{*}{ Wright } & Positive & 29 & 1 \\
& Negative & 60 & 27 \\
\hline
\end{tabular}

Sensitivity $=32.5 \%\left(\mathrm{CI}_{95 \%}: 22.8-42.3\right):$ Specificity $=96.4 \%\left(\mathrm{CI}_{95 \%}\right.$ : 89.5-100): Positive Predictive Value (PPV) $=96.6 \%\left(\mathrm{CI}_{95 \%}\right.$ : 0.9-100): Negative Predictive Value $(\mathrm{NPV})=31 \%\left(\mathrm{CI}_{95 \%}: 21.3-40.7\right)$ : False Negative: 67.4\% ( $\mathrm{CI}_{95 \%}$ : 49.7-85.1): False Positive: 0.035: Positive Likelihood Ratio: 9.12 ( $\mathrm{CI}_{95 \%}$ : 1.3-63.98): Negative Likelihood Ratio: $0.7\left(\mathrm{CI}_{95 \%}: 0.59-0.82\right)$

Table 6: Diagnostic index of Coombs' Wright test in diagnosis of patients suspected to brucellosis

\begin{tabular}{llcc}
\hline & & Brucellosis & \\
& & Positive & Negative \\
\hline Coombs' Wright & Positive & 87 & 0 \\
& Negative & 2 & 27 \\
\hline
\end{tabular}

Sensitivity $=97.7 \%\left(\mathrm{CI}_{95 \%}:\right.$ 94.6-100): Specificity $=100 \%\left(\mathrm{CI}_{95 \%}: 100-\right.$ 100): Positive Predictive Value (PPV) $=100 \%$ ( $\left.\mathrm{CI}_{95 \%}: 100-100\right)$ : Negative Predictive Value $(\mathrm{NPV})=93.1 \%\left(\mathrm{CI}_{95 \%}: 83.8-100\right):$ False Negative: $2.2 \%$ (CI: 0-7.8): False Positive: 0: Positive Likelihood Ratio: Infinity: Negative Likelihood Ratio: 0.022 ( $\mathrm{CI}_{95 \%}$ : 0.005-0.088)

Sensitivity and specificity of Wright were respectively $32.5 \%\left(\mathrm{CI}_{95 \%}\right.$ : $\left.22.8-42.3\right)$ and $96.4 \%\left(\mathrm{CI}_{95 \%}\right.$ : 89.5-100). The Positive Predictive Value (PPV) and Negative Predictive Value (NPV) were 96.6\% (CI $\mathrm{CI}_{95 \%}$ : 0.9$100)$ and $93.1 \%\left(\mathrm{CI}_{95 \%}: 83.8-100\right)$, respectively (Table 4$)$.

Sensitivity, specificity, positive predictive value and negative predictive value for Coombs' Wright were $97.7 \%\left(\mathrm{CI}_{95 \%}\right.$ : 94.6-100), 100\% ( $\mathrm{CI}_{95 \%}$ : 100$100), 100 \%\left(\mathrm{CI}_{95 \%}: 100-100\right)$ and $93.1 \%\left(\mathrm{CI}_{95 \%}: 83.8\right.$ 100), respectively (Table 5 and 6).

\section{DISCUSSION}

In our study 65 persons (53.3\%) were female. In other study incidence of brucellosis in females were reported as 64\% (Hatami et al., 2010), 88\% (Gomez et al., 2008), 34.02\% (Abdi-Liae et al., 2007) and 34.1\% (Afsharpaiman and Mamishi, 2008). High frequency of brucellosis among women in our study is the result of higher frequency of women's contact with cattle and dairy products (production of dairies like cheese, butter and so on is done by women). $57.4 \%$ of our patients were urban and in other studies this rating was $12 \%$ (Gomez et al., 2008) and 41\% (Afsharpaiman and Mamishi, 2008). Using non-pasteurized dairy products is a popular behavior among urban people in this region and some patients have double living sites (urban and rural), because of these factors brucellosis is a common zoonotic disease. The mean age of patients were $40.2( \pm 17)$. In another study the mean age of patients was 41(Gomez et al., 2008) and range of patient's age was somehow similar to our study. Myalgia was the most common symptom and was seen in $85.5 \%$ of patients and low backache was the second most common symptom (84.7\%). In the other study fever $52.9 \%$ (Abdi-Liae et al., 2007), arthritis and arthralgia 79.5\% (Afsharpaiman and Mamishi, 2008), fever 83.8\% (Hajia et al., 2009) were the most common symptom.

Leucopenia, anemia and thrombocytopenia were observed in $21.8 \%, 21.7 \%$ and $10.8 \%$ of our patients, respectively. In other study leucopenia was reported differently from $13.6 \%$ to $31.8 \%$ (Abdi-Liae et al., 2007; Afsharpaiman and Mamishi, 2008; Hatami et al., 2010), anemia was reported as $43.5 \%$ (Abdi-Liae et al., 2007), 56.8\% (Afsharpaiman and Mamishi, 2008) and thrombocytopenia was reported as $12.5 \%$ (Abdi-Liae et al., 2007) and 9.1\% (Afsharpaiman and Mamishi, 2008). These differences can be related to race, diet and other environmental factors in different regions.

In our study Wright test was considered positive if its titer was equal or greater than 1/160. Coombs' Wright was considered positive if its titer was equal or greater than $1 / 40$. In other study titer $1 / 80$ and $1 / 160$ (Karami and Movassagh 2010), 1/80 and 1/80 (Hatami et al., 2010), 1/80 and both titers of 1/80 (Abdi-Liae et al., 2007) and 1/40 (Hajia et al., 2009) for Wright and Coombs' Wright respectively were considered positive. Like the other study and based on recommendation of CDC of Iran we selected Wright of $1 / 160$ and Coombs' Wright of $1 / 40$ as positive.

In our study sensitivity, specificity, positive predictive value and negative predictive value were 32.5, 96.4, 966 and 93.1\%, respectively. Taleski et al. (2002) study the sensitivity of Wright and Coombs' Wright were 84 and $86 \%$. The specificity of Wright and Coombs' Wright were $100 \%$ for both methods. In the other study Wright were positive in all cases except one and Coombs' Wrights were positive in all cases (Rajaii et al., 2006). In two other studies titers of Coombs' Wright were more than Wright (Gomez et al., 2008; Heydari et al., 2008). In one study sensitivity of Wright and Coombs' Wright were 97.7 and 100\% respectively (Afsharpaiman and Mamishi, 2008).

Culture is the gold standard of diagnosis of brucellosis (Lucero et al., 2007; Araja and Awar, 1997; Hajia et al., 2007; 2009; Taleski et al., 2002), but this method is difficult and time-consuming (Parizadeh et al., 2009; Rajaii et al., 2006; Taleski et al., 2002) and its sensitivity is reported as 10-30\% (Kazemi et al., 2008; Parizadeh et al., 2009). Therefore we consider clinical, serology and responses to treatment as definite definition. 
Now it can be concluded that sensitivity of Coombs' Wright is more than Wright. Coombs' Wright can be used as the first screening test and it is the best screening test for diagnosis of brucellosis. We propose Coombs' Wright for screening and we believe that 2ME test can be done on Coombs' Wright and Wright test can be omitted from panel of diagnostic tests of brucellosis. This strategy can also decrease cost of diagnosis and can reduce confusion about interpretation of tests. Therefore, we suggest Coombs' Wright test for all patients suspected to brucellosis and we may use $2 \mathrm{ME}$ in order to discriminate acute, chronic and exposure to antigen and 2ME on Coombs' Wright specimen is enough to follow up the disease.

\section{CONCLUSION}

Coombs' Wright is more sensitive than Wright for diagnosis of brucellosis. Instead of considering Wright, Coombs' Wright and 2ME (mercaptoethanol) tests and interpretation of these three test we can just apply Coombs' Wright and 2ME to reduce the expenditures and use a more sensitive test for diagnosis of brucellosis.

\section{ACKNOWLEDGMENT}

We thank all staffs of infectious diseases ward in Tohid hospital.

\section{REFERENCES}

Abdi-Liae, Z., A. Soudbakhsh, S. Jafari, H. Emadi and K. Tomaj, 2007. Haematological manifestations of brucellosis. Acta Med.. Iranica, 45: 145-148.

Afsharpaiman, S. and S. Mamishi, 2008. Brucellosis: review of clinical and laboratory features and therapeutic regimens in 44 children. Acta Med. Iranica, 46: 489-494.

Aliskan, H., 2008. The value of culture and serological methods in the diagnosis of human brucellosis. Mikrobiyol. Bul., 42: 185-195. PMID: 18444578

Araja, G.F. and G.N. Awar, 1997. The value of ELISA vs. negative Coombs findings in the serodiagnosis of human brucellosis. Serodiagnosis Immunotherapy Infect. Dis., 8: 169-172. DOI: 10.1016/S0888-0786(96)01073-6

Gomez, M.C., J.A. Nieto, C. Rosa, P. Geijo and M.A. Escribano et al., 2008. Evaluation of seven tests for diagnosis of human brucellosis in an area where the disease is endemic. Clin. Vaccine Immunol., 15: 1031-1033. DOI: $10.1128 / C V I .00424-07$ PMid:18448622
Hajia, M., M. Rahbar and F. Keramat, 2009. Epidemiological, clinical, diagnostic and treatment aspects of hospitalized Brucellosis patients in Hamadan. Ann. Trop. Med. Public Health, 2: 4245.

Hajia, M., M. Rahbar, H.A. Taghavi, 2007. Brucellosis antibody level of hospitalized patients in hamadan, Western Iran. Shiraz E Med. J., 8.

Hatami, H., M. Hatami, H. Soori, A.R. Janbakhsh and F. Mansouri, 2010. Epidemiological, clinical, and laboratory features of brucellar meningitis. Arch. Iran Med., 13: 486-491. PMID: 21039003

Heydari, F., N.A. Mozaffari and A. Tukmechi, 2008. Comparison of Standard Seroagglutination Tests and ELISA for Diagnosis of Brucellosis in West Azerbaijan Province, Iran. Res. J. Biol. Sci., 3: 1460-1462.

Karami, A.R. and M.H. Movassagh, 2010. Seroprevalance of brucellosis in human population in northwest region of Iran. Global Vet., 4: 626627. Available: www.idosi.org/gv/gv4(6)10/18.pdf

Kazemi, B., S.A. Yousefi Namin, M. Dowlatshahi, M. Bandepour and F. Kafilzadeh et al., 2008. Detection of brucella by peripheral blood PCR and comparison with culture and serological methods in suspected cases. Iranian J. Publ. Health, 37: 96102.

Lucero, N. E, Ayala, S.M, Escobar, G.I and Jacob, N.R 2007. The value of serologic tests for diagnosis and follow up of patients having brucellosis. Am. J. Infect. Dis., 3: 27-35. DOI: 10.3844/ajidsp.2007.27.35

Parizadeh, M.J.M.S., M.R. Erfanian and M.A. Nezhad, 2009. A survey on antibody levels among individuals at risk of brucellosis in khorasan razavi province, Iran. Pak. J. Nutr., 8: 139-144. DOI: 10.3923/pjn.2009.139.144

Rajaii, M., B. Naghili and A. Pourhassan, 2006. Comparison of ELISA and STA tests in diagnosis of brucellosis. Iranian J. Clin. Inf. Dis., 1: 145-147.

Taleski, V., L. Zerva, T. Kantardjiev, Z. Cvetnic and M. Erski-Biljic et al., 2002. An overview of the epidemiology and epizootology of brucellosis in selected countries of central and southeast Europe. Vet. Microbiol., 90: 147-155. DOI: 10.1016/S0378-1135(02)00250-X 